\section{Meditação de MÉtodo}

Method MEDITATION

\author{
Jean-Luc Nancy
}

Universidade Marc Bloch

Estrasburgo, França

\title{
Resumo
}

O artigo aborda a reflexão sobre o método na tradição filosófica, evocando especialmente Descartes, Hegel e Heidegger, no intuito de especular sobre a especificidade do pensamento de Georges Bataille. Retomam-se, assim, noçóes importantes como comunidade, impossível, não-saber, entre outras

\section{Résumé}

L'article aborde la réflexion sur la méthode dans la tradition philosophique, évoquant notamment Descartes, Hegel et Heidegger, dans le but de spéculer sur la spécificité de la pensée de Georges Bataille. On y reprend, ainsi, des notions comme celles de communauté, d'impossible, de non-savoir, entre autres.

\section{Abstract}

This article discusses the debate on method in the philosophical tradition, evoking especially Descartes, Hegel and Heidegger, in order to speculate on the specific thought of Georges Bataille. It speculates, on concepts such as community, impossible, not-knowing, among others.

"Que se leia Aristóteles ou que se leia Descartes, não se deve acreditar a princípio nem em Aristóteles, nem em Descartes; mas somente meditar como eles fizeram ou como tiveram que fazer, com toda a atenção de que se for capaz, e em seguida obedecer à voz de nosso Mestre comum \& nos submeter de boa fé à convicção interior \& àqueles movimentos que sentimos ao meditar.”

Não há, portanto, qualquer método particular que se deva preferir, nem método geral que permita julgar diversos métodos. Mas há, antes de tudo, a necessidade de aderir ao movimento de um espírito, de entrar em sua maneira e em sua via - que são os dois aspectos que podemos encontrar no que chamamos "método" - depois, é preciso voltar para o movimento próprio de nosso espírito, que, se for sincero, não pode deixar de encontrar nele o eco da voz divina - ou da nudez - que somente pode dizer a verdade.

Palavras-chave: Georges Bataille; método; comunidade; não saber.

Mots-clés: Georges Bataille; méthode; communauté; non-savoir.

Keywords: Georges Bataille; method; community; notknowing. 
Em outras palavras, que seriam as de Espinosa, a verdade se manifesta por si mesma e, ao se manifestar, ela se faz sentir com um sentimento ou uma sensaçáo que náo deixa de ser uma tecla sensível por estar ligada ao espírito - o próprio sentido do verdadeiro ou, ainda, o verdadeiro como impressão sensível que nos chega de um fora cuja exterioridade, contudo, não é nada senão a mais profunda intimidade deste espírito ou daquilo que assim nomeamos. Mas isso não é outra coisa senão precisamente o movimento pelo qual o verdadeiro abre sua passagem segundo as inflexóes, as atençôes e as paixóes de cada um que medita, para retomar a expressão empregada por Malebranche. O que é isto, consequentemente, senão um movimento que depende, sem dissociação, da singularidade de um ou de outro e da universalidade do verdadeiro?

Seria isto dizer que toda singularidade toca o mesmo universal? Sem dúvida que não, pois este último se modula, se modaliza, se modifica, até mesmo se modela segundo a meditação singular. $\mathrm{O}$ universal do verdadeiro é, portanto, ao mesmo tempo um e múltiplo. Ele é um multiverso ou um pluriverso, como diz a física. De modo algum, uma pluralidade dispersa, errática e empoeirada em todos os sentidos da palavra, mas uma disseminação de si do "Um" que nós nos representamos com razão como devendo ser a condição do verdadeiro.

Ora, a meditação deve ser ela mesma plural não somente para se afinar à multiplicidade de universos no universo - pois isso seria limitá-la a reencontrar sempre um só, único e último termo enquanto que este (primeiro ou último, é a mesma coisa) vale apenas para formar o foco da disseminação, que não dissipa uma única semente, mas muito mais a infinidade de sementes das quais a dispersão é a regra, o princípio, e por fim, a forma verdadeira.

A meditação é plural porque seu porte singular não é outra coisa senão a própria disseminação, na medida em que ela se encontra, se reconhece e se aprova. Este sentimento de si é o mesmo em qualquer ocasião, em qualquer ocorrência, mas ele só é o mesmo se nele o verdadeiro for sentido e comunicado, não sendo, contudo, a cada vez senão o verdadeiro daquele encontro preciso, de seu movimento, de seu caráter insubstituível. A meditação pode se tornar vertiginosa? É talvez em um sentido a questão. Mas em primeiro lugar ela é em ato, nenhum protocolo a precede. 
Ao nomear um "método meditação", Bataille reencena da maneira mais profunda e mais aguda o sentido desse ato, seu sentido que sempre implica relação sensível a um fora - o outro, ou a noite.

A meditação é prática, ou seja, ela é um ato, um procedimento efetivo e concreto em que o corpo se engaja tanto quanto a alma, em que a alma testemunha da melhor forma esta extensão, que segundo Descartes, é a sua e a dispóe em todas as partes do corpo. Ela é o pensamento no seu ato de pesar - segundo sua etimologia - o que quer dizer tanto ponderar [soupeser] a coisa (o ser, o sentido, o verdadeiro) quanto se apoiar sobre ela, nela. É ainda Descartes - ele que nos parece tão fortemente ser o herói tanto quanto o arauto de uma espécie de metodologia primeira - que precisa bem que o método é uma prática: "eu não digo Tratado do Método mas Discurso do Método, o que é o mesmo que Prefácio ou Opinião referente ao método, para mostrar que eu não tenho intenção de ensiná-lo, mas somente de falar sobre ele. Pois, como se pode ver do que eu digo a respeito do método, ele consiste mais em prática que em teoria."

Bataille leitor de Descartes, de Hegel, bem como de Nietzsche, eis a meditação: ela chega a meditar sobre a própria filosofia. Hegel enuncia o desafio de uma maneira que nenhum filósofo recusa - pelo contrário, seria possível mostrar sem dificuldade que todos dizem, em sua inconciliável disseminação, a mesma coisa que ele.

"O método é [...] não uma forma exterior, mas a alma é o conceito do conteúdo, do qual ela só difere na medida em que os momentos do conceito vêm também, neles mesmos, na sua determinidade, aparecer como a totalidade do conceito." Mas é evidente que esse "aparecer como a totalidade" não passa de um momento passageiro - aquele da "totalidade sistemática que é apenas uma Ideia una" e não é ainda a Ideia segundo sua vida e sua livre saída para fora de si mesma (da qual fala a sequência do texto).

"É que uma filosofia, quando está em sua plena virulência, nunca se apresenta como uma coisa inerte, como a unidade passiva e já acabada do saber; nascida do movimento social, ela mesma é movimento [...]. Toda filosofia é prática, mesmo aquela que a princípio parece mais contemplativa." Assim se exprime Sartre no início de sua Questão de método cujo título se encontra assim de alguma maneira deportado, senáo desqualificado pelo texto. Con- 
temporâneo de Bataille, que ele pensa não compreender, não admitir, Sartre está mais próximo dele do que acredita.

No entanto, é preciso dizer mais, pois isto que "parece" contemplativo e que pode realmente sê-lo tanto quanto quisermos, não é por isso menos prático. A contemplação nos reconduz à meditação da qual a princípio ela era o resultado. Se a meditação se adentra no "objeto" - na questâo, na preocupação, na emoção - e se deixa ao mesmo tempo penetrar por ele, é para conseguir entrar com ele nesta relação nomeada contemplação ou adoração, definida por uma correspondência íntima, uma afinidade, um contato e também um modo de endereçamento mútuo.

Não é por isso que se trate de se fundir no objeto para dele não mais se distinguir, tornando-se assim incapaz de apresentar aquilo que, no entanto, da coisa mesma e do movimento que a ela se reúne, exige ser dito. Schelling recusa a contemplação na medida em que "tomada por si mesma", ela permanece "muda" enquanto deveria "alcançar a expressão". Mas esta última deve, por sua vez, ao se distanciar da confusão com o objeto, permitir "estabelecê-lo firmemente diante de si" e "contemplá-lo novamente no entendimento, como num espelho".

É por isso que a contemplação deve também ser designada "adoração", que implica palavra, e palavra não apenas remetida à coisa, numa oraçâo fervorosa, mas também enunciada para o espírito - o meu, o de todos - de formas orais e mesmo oratórias próprias para destacar a sua verdade, esta verdade que é a cada vez a verdade da coisa.

De certa forma, o exame atento disto que "método" implica através das filosofias não está longe de perturbar a aparência inicial de uma "metodologia".

Que não se trata de uma ordem de meios é o que já nos ensinava a meditação. Esta se distingue da reflexão ou do discurso (da conversa, do tratado, da entrevista) no que ela não desdobra uma instrumentação ou uma progressão, mas se agrega mais numa penetração, se concentra numa adesão.

Ao introduzir seu "Método de meditação", Bataille experimentava a necessidade de manter a distância o registro do meio. Ele o faz afastando a tentação que poderia constituir um ensinamento à maneira da ioga. 
... a concentração lenta, irônica, de pensamentos em direção a um vazio, ao escamoteamento hábil do espírito sobre temas de meditação [...] poderiam ser objeto de ensino [...] não há meio mais curto de furtar-se à "esfera da atividade".

No entanto, replica ele: "se recorrer aos meios define a esfera da atividade, como arruiná-la, quando desde o início falamos de meios"? A filosofia, sem dúvida, nunca sai da esfera da atividade na medida em que apresenta desde sempre uma exigência de método, que se propóe, ela mesma, como exigência de meios em vista de um fim. Segundo o próprio Bataille, a causa da filosofia é assim entendida. Sua subordinação a fins a exclui por princípio do que ele nomeia aqui meditação para, diz ele, usar uma palavra menos fastidiosas do que expressóes tais como "experiência interior" ou "operação soberana". O que essas denominaçôes visam é sempre um ato ou um gesto que na insubordinação pode levar à vertigem - como o riso, o sacrifício, a poesia, a embriaguez, a "efusão erótica". É no mesmo texto que Bataille escreve "eu penso como uma moça tira o vestido".

Ele admite, contudo, que a palavra "meditação" é "de aparência piedosa" - desejando que essa aparência, em seu texto, seja dissipada - mas o que ele não ressalta e que, no entanto, não pode lhe ser desconhecido é que a palavra foi também pronunciada pelos filósofos, muito antes de Descartes e mesmo antes do cristianismo (meditatio é uma palavra presente nos estoicos e seu valor de reflexão atenta, de preocupação penetrada, retoma um valor do grego mélétâ, tomar cuidado, estudar, cultivar - como na célebre mélétè thanatou, "meditação da morte" ou em seu simétrico mélétè to pan, "cuide do todo").

Não se trata de substituir "método" por "meditação" e, sobretudo, não como se quiséssemos substituir a meditação do meio por uma imediatez fusional - com a qual, no entanto, não se deve confundir as vertigens bataillianas, a sufocação, o mal-estar. Trata-se somente de bem discernir até que ponto o método representa para a filosofia - para o exercício da filosofia e para o exercício que ela é - ao mesmo tempo a exigência de se recusar ao êxtase, à efusão, ao oráculo e à cegueira sobre o caráter necessariamente primeiro, inicial e mesmo iniciador da verdade que nos chega, que nos requer, que se faz desejar antes de tudo e em tudo (nas coisas, nas pessoas e nas obras) - e que sem dúvida não impede de beirar a vertigem. 
O sentido não é uma teleologia da significação - um objetivo da história ou da vida - mas está na passagem incessante, na circulação ininterrupta entre todos os pontos de verdade cuja disseminação forma - paradoxalmente - o mundo ou os mundos que habitamos sem que eles abram para qualquer outro mundo; abrindo, todavia, para uma vertigem neste mundo, um desvanecimento, com o coração na boca.

A circulação do sentido não é nem uma mediação, nem uma imediatidade: é uma relação, não é uma atividade, mas não é uma inação. É um exercício, mas sem finalidade. É uma proximidade segundo o espaçamento dos singulares. É uma passividade, pois é a paixão sem a qual, muito simplesmente, ninguém consentiria em viver, em existir.

O sentido é sem método, ele abre caminhos sempre novos e sempre repercorridos; suas interrupçóes, seus mergulhos no fundo das florestas, dos oceanos, das galáxias ou dos coraçóes, seus suspenses e seus desabamentos são os tantos pontos verídicos, os tantos nascimentos e mortes com que conta a imensidão de espaçotempo diante da qual, ou melhor, na qual uma vertigem nos toma - uma vertigem de verdade, da verdade una e infinitamente plural.

Bataille é o único a perceber verdadeiramente e por ele mesmo o fogo que se acende na relação ou como relaçáo. Digo "por ele mesmo" para distinguir Bataille daqueles que podiam no mesmo momento recorrer a velhas engrenagens de entusiasmo patriótico, nacionalista, conservador-revolucionário, fantasmático ou paranoico. Ele foi o único e por isso sempre foi olhado como um pensador nos limites seja da contradição íntima, seja do misticismo suavemente delirante.

É verdade que, a partir do momento em que se considera Bataille com sangue-frio, não se pode deixar de observar um suspense, uma reserva. A comunidade para ele é fusão, liberação do desejo de ser no outro, fim da única companhia dos mesmos no heterogêneo útil e acesso ao êxtase erótico ou sacrificial no qual apenas se encontra aquilo que é mais que um povo, mais que um nós e que deveria abrir os seres à verdade daquilo que os subtrai ao mundo sempre insuficiente da coexistência dos interesses e dos projetos.

Acabo de dizer "insuficiente", mas esta não é uma palavra apropriada para Bataille: ele não se preocupa com suficiência, com 
completude, com satisfação. Ele só tem o sentido do excesso, do transbordamento, do desejo renovado. É o único pensador do acesso ao impossível - este impossível que ele comunicou a Lacan, por exemplo, que não soube muito bem o que fazer com isso que eu nomeio aqui "acesso". Pois Bataille escreve "a verdade nós alcançamos..." acrescentando em seguida que isto (este "alcançar") não se sustenta, mas tendo afirmado que "nós alcançamos". Ele diz também, eu bem o sei, que o eros ou o sacrifício são para terminar sempre em comédia. A comédia ignora o acesso ao impossível. Contudo, Bataille permite as duas leituras: no mesmo ponto, nós alcançamos e um riso eclode. O riso também testemunha o acesso realizado - e perdido.

A comunidade, portanto, nós a alcançamos e a perdemos. Bataille acentuou a perda quando ele teve de reconhecer que nenhuma forma de comunidade - nem política, nem erótica (ainda que ele tenha deixado mais chances à comunidade dos amantes) não chega a se realizar - ou a alcançar sua plenitude. É por isso que eu havia tentado jogar uma outra carta, se assim posso dizê-lo, aquela de uma "comunidade inoperante", que teria significado: a partilha comum de um impossível ser comum. Portanto o "em" comum, o "em" ou o "entre" do comum como seu signo verdadeiro.

Partilhar um impossível, ou partilhar um "não saber" - para retomar uma outra expressão de Bataille -, ou ainda partilhar algo que excede toda partilha por não ser nada que se possa dividir, repartir ou trocar - e no entanto é alguma coisa, é a coisa mesma que nos lança a todos no mundo ou ainda, é nela que somos lançados sob o nome "mundo"... É algo assim que Bataille me impeliu a buscar. Mas, para permanecer nele, é preciso dizer novamente como esta "força", esta impulsão vinda dele é forte e não é em nada diminuída com o tempo. Resta aquilo que até aqui melhor designou um desejo de que não podemos nos desprender.

O que é uma moça que tira o vestido? Ou ainda, para ser politicamente correto, um rapaz que tira sua calça? É alguém que se entrega ao desejo - ao desejo do outro como ao seu próprio desejo, ao desejo de ser desejado pelo outro. E de arriscar-se a aí se perder. Ou ainda, no saber estranho, néscio (inconsciente talvez, mas antes "consciente sem ciência") daquilo que ele sabe, da certeza de uma perda, mas de uma perda na qual não é mais questão distin- 
guir "perda" e "ganho", pois não se trata mais de bens apropriáveis ou expropriáveis.

Não está aí a conjunção de Ereignis e de Enteignis da qual fala Heidegger? Mas sem omitir acrescentar, como o faz Heidegger, Zueignis, ou seja, "dedicatória", "atribuição ou imputação a...”. A quem? Ao outro. A moça ou o rapaz se dá ao outro. "Se dar", se abandonar: ser para [être à]... - em um sentido que excede o pertencimento, a propriedade, em um sentido que está muito mais ligado ao "sein zu" como no Sein zum Tode que se traduz por "ser para a morte" embora náo se trate de uma finalidade, nem mesmo de uma direção, mas de uma exposição.

Um outro "ser para" não está longe: o in sein no sentido do in der Welt sein que traduzimos por "ser no mundo"1 [être au monde] pois não se trata do "em" [dans], "dentro" evocado primeiramente pelo in. Mas, de todas as formas, "ser" é "ser para" [être ̀̀]... - e os três pontos, os pontos ditos de suspensão, as reticências, são aqui essenciais. Ora, as reticências são frequentemente notáveis em Bataille. Elas designam um inacabamento que acaba, uma imersão para além das palavras que sem última palavra, volta para concluir. Cito o fim de L’impossible (logo antes do "Epílogo"): "Eu posso me dizer assim da minha reflexão infeliz, que sem a extrema angústia teria sido pesada, que ela me deixa, no momento em que vou sucumbir, o domínio (empire)..." - e é necessário salientar que esta palavra, o "Empire" com maiúscula, é o título da parte (nem bem duas páginas) que se conclui aqui. O "Epílogo" que segue verá aparecer uma menina que se joga sobre o narrador para desnudá-lo...

Não há filosofia senão assim, desnudada, desprendida de todo objeto, ou entâo só há disciplina morna e doutrina ou visão de mundo. Heidegger soube disso, mas ao preço de uma ênfase que leva a crer que o pensamento captura a coisa em vez de dela se desprender. Dir-se-á que Bataille pratica uma outra ênfase? Não se poderá fazê-lo, pois já o recurso à ficçáo e na ficção em primeira pessoa representa um desvio pelo qual retorna uma condição de verdade: digo aquilo que posso dizer e digo o suspense ao qual me aferro.

\footnotetext{
'Tendo sido convencionadas as traduçóes dos termos heideggerianos "sein zu" e "in der Welt sein" por "ser para", e "ser no mundo" no português, optamos aqui por manter as convençóes, ainda que se neutralize o jogo que Nancy está propondo entre o "être ă" e o "être au monde". (N. do T.)
} 
Quanto à roupa tirada e à nudez que goza - e sofre - sabemos, com todo o (não) saber possível, a que ponto ela é insignificável, insignificante e fazendo sentido exatamente assim.

A questão do ser-junto é a própria questão do sentido. Ela exige primeiramente que compreendamos - que meditemos - até que ponto o ser é junto e não é diferentemente (quer dizer também que "diferentemente do que ser" vale por "ser junto", e que "ser" só ou "o ser" ao modo de Heidegger (mas se negligenciamos nele o apelo ao verbo!) é e permanece só... Se o ser é junto (não "é o conjunto", pois "o conjunto" não existe) então ser é ser junto, e é o ser todos, humanos, animais, vegetais, minerais, vivos, mortos, fictícios, reais. Mas uma vez que o conjunto ${ }^{2}$ não existe - não somente o grande conjunto universal mas cada espécie ou cada modo de conjunto, amantes ou grupo, coleção ou vizinhança - isto implica que não se chega lá, que não se deve chegar lá. Isto não é uma falta, é uma abertura: podemos estar abertos a isso de que estamos impedidos de nos apropriar. Nós tocamos aí - nós tocamos aí frequentemente e esse tocar acede à verdade. Que tão logo se esquiva em si mesma, vestido tirado.

Tradução de Paola Ghetti

(Doutoranda em Teoria Literárial UNICAMP)

Jean-Luc Nancy é filósofo e professor emérito da Universidade Marc Bloch de Estrasburgo. É autor de obras importantes como L'absolu littéraire: Théorie de la littérature du romantisme allemand (1978), em coautoria com Philippe Lacoue-Labarthe, Le partage des voix (1982), La Communauté désouvrée (1983), Corpus (1992), Le sens du monde (1993), Etre singulier pluriel (1996), La création du monde ou la mondialisation (2002), La déclosion (2005), Tombe de sommeil (2007), entre outros. Mais recentemente, publicou Maurice Blanchot, passion politique (2011), Dans quels mondes vivons-nous (com Aurélien Barrau, 2011) e L'Équivalence des catastrophes (2012). E-mail: <jean-luc.nancy@orange.fr>.

\footnotetext{
${ }^{2}$ Nancy aqui faz uma relação entre o verbo "être" e os dois sentidos da palavra "ensemble". No primeiro caso, traduzimos "être ensemble" por "ser junto"; no segundo, optamos por traduzir "ensemble" por "conjunto", dada a variação conotativa do verbo no contexto da frase. (N. do T.)
}

Recebido em 05/09/2012 Aprovado em $12 / 10 / 2012$ 